\title{
A global clinical measure of fitness and frailty in elderly people
}

\author{
Kenneth Rockwood, Xiaowei Song, Chris MacKnight, Howard Bergman, David B. Hogan, \\ Ian McDowell, Arnold Mitnitski
}

\section{Abstract}

Background: There is no single generally accepted clinical definition of frailty. Previously developed tools to assess frailty that have been shown to be predictive of death or need for entry into an institutional facility have not gained acceptance among practising clinicians. We aimed to develop a tool that would be both predictive and easy to use.

Methods: We developed the 7-point Clinical Frailty Scale and applied it and other established tools that measure frailty to 2305 elderly patients who participated in the second stage of the Canadian Study of Health and Aging (CSHA). We followed this cohort prospectively; after 5 years, we determined the ability of the Clinical Frailty Scale to predict death or need for institutional care, and correlated the results with those obtained from other established tools.

Results: The CSHA Clinical Frailty Scale was highly correlated $(r=0.80)$ with the Frailty Index. Each 1-category increment of our scale significantly increased the medium-term risks of death $(21.2 \%$ within about $70 \mathrm{mo}, 95 \%$ confidence interval [Cl] $12.5 \%-30.6 \%)$ and entry into an institution $(23.9 \%$, 95\% $\mathrm{Cl} 8.8 \%-41.2 \%$ ) in multivariable models that adjusted for age, sex and education. Analyses of receiver operating characteristic curves showed that our Clinical Frailty Scale performed better than measures of cognition, function or comorbidity in assessing risk for death (area under the curve 0.77 for 18month and 0.70 for 70 -month mortality).

Interpretation: Frailty is a valid and clinically important construct that is recognizable by physicians. Clinical judgments about frailty can yield useful predictive information.

CMAJ 2005;173(5):489-95

$\mathrm{F}$ railty is a term widely used to denote a multidimensional syndrome of loss of reserves (energy, physical ability, cognition, health) that gives rise to vulnerability. It appears to be a valid construct, but how exactly to 5 define it remains unclear. ${ }^{1-8}$ There are many operational definitions,,$^{1,5,9-13}$ which typically are rules-based; for example, a person may be defined as frail if 3 or more symptoms (of unintentional weight loss, feeling exhausted, weak grip strength, slow walking speed and low physical activity) are present. $^{5}$ Rules-based definitions often are derived from multiple regression analyses and can be speciously precise, for example in requiring combinations of factors that might not apply to an individual case.

Summing the number of impairments is another way to define frailty. ${ }^{2}$ Despite its strong predictive validity, ${ }^{2,14,15}$ this approach is time-consuming and not widely used clinically. A third class of operational classifications, which in this report we attempt to extend, relies on clinical judgment to interpret the results of history-taking and clinical examination. ${ }^{16,17}$

The creation of so many scales to measure frailty reflects uncertainty about the term and its components. The ability to measure frailty is useful at a health care policy level as well as clinically: Information about frailty helps program planners by identifying the range of services that might be required and the anticipated need for them. Clinically, frailty stratification can help to plan interventions or to predict a patient's risk of death or need for institutional care. Because the scales are intended to stratify risk, the ability to predict adverse outcomes serves a common goal.

In the Canadian Study of Health and Aging (CSHA), we have worked with 3 approaches. First, like other groups, we developed a rules-based definition of frailty. ${ }^{12}$ Later, we developed (and still actively work with) a method of counting a patient's clinical deficits (identified by means of signs, symptoms and abnormal test results). This approach is reproducible and correlates highly with mortality, ${ }^{2}$ but in clinical use the deficit count is unwieldy. In this paper, we describe our third approach: the derivation and validation of the Clinical Frailty Scale, a measure of frailty based on clinical judgment.

\section{Methods}

The CSHA is a representative 5-year prospective cohort study. Its first stage of investigation (CSHA-1) began in 1991 with 10263 people aged 65 years and older, recruited with the aim of describing the epidemiology of cognitive impairment and other important health issues in elderly Canadians. ${ }^{18-20}$ From the clinical examinations we did within this cohort, we developed the rulesbased frailty definition ${ }^{12}$ and the Frailty Index, a measure of frailty obtained by counting various clinical deficits (Appendix 1). Afterward, we also developed CSHA scales for function and overall clinical frailty, with the goal of creating tools that could stratify elderly patients as to their relative degree of vulnerability (i.e., 
their risks of death and of entry into an institutional facility) with simple clinical descriptors. We defined the Clinical Frailty Scale using the terminology of Streiner and Norman. ${ }^{21}$ Rooted in our theoretical model of fitness and frailty ${ }^{7}$ and the importance of function (which we reported in earlier investigations), ${ }^{12}$ our Clinical Frailty Scale (Box 1) ranges from 1 (robust health) to 7 (complete functional dependence on others).

In 1996, we began CSHA-2, the second stage of the study. Of the 10263 people in CSHA-1 who had been examined clinically and found to be without dementia, 2305 (22.5\%) were examined again by one of a team of clinicians (33 family physicians, 30 internists or geriatricians, 11 neurologists and 3 psychiatrists), who then applied the Clinical Frailty Scale and the other measures in Box 2, for comparison. This reduced study population (874 men [37.9\%] and 1431 women) consisted of 210 people (9.1\%) who had entered institutional facilities since CSHA-1; 1326 (57.5\%) who were still living at home or elsewhere in the community and whose $3 \mathrm{MS}$ screening results in CSHA-2 now indicated cognitive impairment (i.e., a 3MS score of 77 or less); and 769 (33.4\%), also living within the community, whose $3 \mathrm{MS}$ scores remained at 78 or greater and who formed a comparison group.

Our objective in the present study (CSHA-3), begun in 2001, was to validate the Clinical Frailty Scale by following those patients who remained alive 5 years after CSHA-2 (1299/2305 [56.4\%]). Follow-up vital and domicile status (living in the community or in an institution) was known for all 2305 participants who did not have dementia at the time of CSHA-2, of whom 249 had entered an institutional facility between CSHA-2 and -3 .

At the end of the clinical interview in CSHA-2, the interviewing physician assigned the subject a score of 1 to 7 on the Clinical Frailty Scale. Each interview was reviewed and scored again by a multidisciplinary team that included the physician and therefore was not blinded to the initial score.

Given the increased likelihood of falls, episodes of delirium and cognitive impairment among people who are frail, we recorded that information. Physicians making the initial Clinical Frailty Scale assessment had access to diagnoses and assessments related to these variables and other measures of comorbidity, function and associated features that inform clinical judgments

\section{Box 1: The CSHA Clinical Frailty Scale}

1 Very fit - robust, active, energetic, well motivated and fit; these people commonly exercise regularly and are in the most fit group for their age

2 Well - without active disease, but less fit than people in category 1

3 Well, with treated comorbid disease - disease symptoms are well controlled compared with those in category 4

4 Apparently vulnerable - although not frankly dependent, these people commonly complain of being "slowed up" or have disease symptoms

5 Mildly frail - with limited dependence on others for instrumental activities of daily living

6 Moderately frail - help is needed with both instrumental and non-instrumental activities of daily living

7 Severely frail - completely dependent on others for the activities of daily living, or terminally ill

Note: $\mathrm{CSHA}=$ Canadian Study of Health and Aging about the severity of frailty. They were, however, unaware of subjects' results on other frailty indexes. The subjects assessed were almost always new to the clinician involved.

To assess the construct validity of the CSHA Clinical Frailty Scale, in the analysis we compared patients' scores from the initial assessments only with their results from other established tools that indicate the degree of frailty by measuring function and comorbidity $^{1}$ (see Box 2). ${ }^{12,23-26}$ When applying the CSHA Function Scale, we excluded "walking" and "transferring" because data from nursing homes were incomplete for many patients.

The Frailty Index is a count of 70 clinical deficits from the CSHA clinical assessment (Appendix 1). Items included the presence and severity of current diseases, ability in the activities of daily living, and physical and neurological signs from the clinical examinations. Each deficit was dichotomized or trichotomized and mapped to the interval $0-1$ (i.e., individual assessment items could be scored as $0,0.33,0.50,0.67$ or 1.0$)$ to represent the severity or frequency of the problem (see Box 2). No variable had more than 5\% missing data. Except for the Clinical Frailty Scale (which was completed on all but 8 patients), any values that were missing were imputed using the relevant mean.

We used Pearson or Spearman correlation coefficients to measure the degree of correlation (i.e., to test convergent construct validity) between the Clinical Frailty Scale and the other, established measurement tools. To assess predictive validity, an aspect of criterion validation, ${ }^{21}$ we constructed Kaplan-Meier curves per

Box 2: Tools for measuring degree of frailty that were compared with the CSHA Clinical Frailty Scale*

- Modified Mini-Mental State Examination ${ }^{22}$ (3MS), in which a scoret of 77 or less indicates cognitive impairment

- Cumulative Illness Rating Scale, ${ }^{23}$ a comorbidity measure that has been validated with autopsies

- A historyt of falls, delirium, cognitive impairment or dementia (as per DSM-III-R criteria for the diagnosis of dementia) ${ }^{24}$

- CSHA rules-based definition of frailty, ${ }_{1}^{12}$ which categorizes subjects as 0 (having no cognitive or functional impairment), 1 (isolated urinary incontinence), 2 (dependent in $1 \mathrm{ADL}$ or having a diagnosis of CIND) or 3 (dependent in at least 2 ADLs, having mobility impairment or having a diagnosis of dementia)

- CSHA Frailty Index, a count of 70 deficits (listed in Appendix 1), including the presence and severity of current diseases, ability in ADLs and physical signs from clinical and neurologic exams. (A person with 7 deficits, for example, would have an index score of $7 / 70=0.10$. The relative frailty or fitness of a patient can be calculated as a percentage difference from the average score for people of that age.) To indicate severity, each deficit not restricted by its nature to two values (i.e., 0 or 1 for absence or presence, respectively) was assigned three $(0,0.5$ or 1$)$ or four values $(0,0.33,0.67$ or 1.0$)$, as appropriate

- CSHA Function Scale (based on the extensively validated Older American Resources Survey), which scores the patient on each of 12 ADLs (some instrumental) as 0 (the patient is independent in carrying out this ADL), 1 (needs assistance) or 2 (is incapable)

Note: $\mathrm{CSHA}=$ Canadian Study of Health and Aging, $3 \mathrm{MS}=$ Modified Mini-Mental State Examination, $\mathrm{ADL}=$ activity of daily living, $\mathrm{CIND}=$ cognitive impairment, no dementia. *Except for the 3MS, a higher score on these tests represents greater morbidity. +The clinicians assessing study participants on the CHSA Clinical Frailty Scale were aware of these factors in the medical history but blinded to scores from all the other indexes listed, except for results from the $3 \mathrm{MS}$ (as indicated). 
scale category. All significance tests were 2-sided; differences were assessed for significance $(p \leq 0.05)$ with the log-rank test. In the multivariable analyses, having first checked for proportionality, we used Cox regression analyses to estimate hazard ratios and construct $95 \%$ confidence intervals (CIs) independently for the $3 \mathrm{MS}$ score $^{22}$ and outcomes of the CSHA Clinical Frailty Scale, and the Cumulative Illness Rating Scale, ${ }^{23}$ as well as the CSHA's Function Scale, rules-based frailty definition ${ }^{12,16}$ and Frailty Index, ${ }^{2}$ adjusting each for age, sex and years of education. Receiver operating characteristic (ROC) curves ${ }^{27}$ were calculated to estimate the areas under the curves for relevant predictor variables in relation to death and entrance into an institutional facility. An intraclass correlation coefficient was used to assess interrater reliability between the 2 Clinical Frailty Scale ratings (i.e., the initial scorings done by physicians and those done later by multidisciplinary teams during CSHA-2).

The research ethics committees of each institution approved the study, and all participants (or their designates) signed informed-consent forms. CSHA funding was chiefly (> 95\%) public and from a variety of sources, as specified in the Acknowledgements. Sponsors had no role in the selection of the objectives or in the analysis, write-up or submission of this report.

\section{Results}

Participants with higher scores on the Clinical Frailty Scale were older and more likely to be female, cognitively impaired and incontinent; to have impaired mobility and function: and to have more comorbid illnesses than those with lower scores (Table 1). They also had higher scores according to both the Frailty Index and the rules-based frailty definition. ${ }^{12,16}$ Of note, at the highest level of frailty our participants had fewer falls, probably reflecting the greater proportion who were bedridden. The degree of correlation between the judgment-based CSHA Clinical Frailty Scale and the mathematically derived Frailty Index was high (Pearson coefficient $0.80, p<0.01$ ), confirming construct validity. The Clinical Frailty Scale and the Frailty

\begin{tabular}{|c|c|c|}
\hline Factor & $\begin{array}{c}\text { Death, } \\
\text { HR }(95 \% \mathrm{Cl})\end{array}$ & $\begin{array}{l}\text { Entry into institution, } \\
\qquad \mathrm{HR}(95 \% \mathrm{Cl})\end{array}$ \\
\hline Age & $1.08(1.07-1.08)$ & $1.15(1.10-1.13)$ \\
\hline Sex & $0.83(0.78-0.89)$ & $1.38(1.21-1.58)$ \\
\hline Education level* & $0.98(0.97-0.99)$ & $0.98(0.97-0.99)$ \\
\hline $\begin{array}{l}\text { Modified Mini-Mental } \\
\text { State Examination }\end{array}$ & $0.84(0.82-0.86)$ & $0.65(0.60-0.70)$ \\
\hline $\begin{array}{l}\text { Cumulative Illness } \\
\text { Rating Scale }\end{array}$ & $1.14(1.11-1.17)$ & $1.22(1.16-1.27)$ \\
\hline \multicolumn{3}{|l|}{ CSHA measuring tools } \\
\hline $\begin{array}{l}\text { Rules-based definition } \\
\text { of frailty }\end{array}$ & $1.17(1.13-1.20)$ & $1.27(1.19-1.35)$ \\
\hline Frailty Index & $1.26(1.24-1.29)$ & $1.56(1.48-1.65)$ \\
\hline Function Scale & $1.16(1.13-1.20)$ & $1.29(1.20-1.39)$ \\
\hline Clinical Frailty Scale & $1.30(1.27-1.33)$ & $1.46(1.39-1.53)$ \\
\hline
\end{tabular}

Note: $\mathrm{Cl}=$ confidence interval, $\mathrm{CSHA}=$ Canadian Study of Health and Aging.

All scales were adjusted for age, sex and number of years of education, and recategorized into 7-level scales to compare with the Clinical Frailty Scale.

*Univariate estimate.

\begin{tabular}{|c|c|c|c|c|c|c|c|}
\hline Characteristic & $\begin{array}{c}1 \\
\text { Very } \\
\text { fit }\end{array}$ & $\begin{array}{c}2 \\
\text { Well }\end{array}$ & $\begin{array}{l}3 \\
\text { Well, with treated } \\
\text { comorbid disease }\end{array}$ & $\begin{array}{c}4 \\
\text { Apparently } \\
\text { vulnerable }\end{array}$ & $\begin{array}{c}5 \\
\text { Mildly } \\
\text { frail }\end{array}$ & $\begin{array}{c}6 \\
\text { Moderately } \\
\text { frail }\end{array}$ & $\begin{array}{c}7 \\
\text { Severely } \\
\text { frail }\end{array}$ \\
\hline Patients, no. & 216 & 260 & 476 & 349 & 305 & 497 & 194 \\
\hline Age, mean (SD), yr & $80.3(5.9)$ & $83.0(6.8)$ & $82.4(6.3)$ & $83.7(6.2)$ & $86.4(6.5)$ & $87.4(6.7)$ & $88.1(7.1)$ \\
\hline Education, mean (SD), grade & $9.6(4.1)$ & $9.9(4.2)$ & $9.6(4.1)$ & $8.8(3.7)$ & $9.7(4.1)$ & $9.4(3.9)$ & $9.1(3.9)$ \\
\hline Women, \% & 51.8 & 58.5 & 57.1 & 56.2 & 64.6 & 68.6 & 80.4 \\
\hline No cognitive impairment, $\%$ & 75.9 & 63.1 & 57.1 & 39.3 & 18.7 & 9.7 & 1.0 \\
\hline $\begin{array}{l}\text { Cognitive impairment, no } \\
\text { dementia, } \%\end{array}$ & 20.4 & 29.2 & 34.9 & 45.6 & 39.7 & 21.5 & 5.8 \\
\hline Dementia, \% & 3.7 & 7.7 & 8.0 & 15.2 & 41.6 & 68.8 & 93.3 \\
\hline With falls, $\%$ & 13.0 & 20.8 & 24.6 & 40.4 & 45.9 & 48.7 & 31.4 \\
\hline With urinary incontinence, $\%$ & 8.3 & 12.3 & 17.2 & 26.6 & 31.8 & 60.4 & 92.8 \\
\hline With impaired mobility, \% & 0.5 & 0.8 & 5.2 & 18.3 & 37.7 & 57.9 & 63.4 \\
\hline $\begin{array}{l}\text { Modified Mini-Mental State } \\
\text { Examination, mean score* (SD) }\end{array}$ & $87.1(9.9)$ & $82.6(13.9)$ & $83.2(12.7)$ & $79.1(13.3)$ & $70.2(17.7)$ & $56.2(22.2)$ & $31.9(21.0)$ \\
\hline $\begin{array}{l}\text { Cumulative IIIness Rating Scale, } \\
\text { mean score (SD) }\end{array}$ & $1.8(1.9)$ & $2.5(2.3)$ & $4.9(2.8)$ & $6.2(3.1)$ & $6.4(3.9)$ & $7.0(4.0)$ & $6.4(4.7)$ \\
\hline \multicolumn{8}{|l|}{ CSHA measurement tools } \\
\hline $\begin{array}{l}\text { Rules-based frailty definition, } \\
\text { mean score (SD) }\end{array}$ & $0.72(1.01)$ & $1.14(1.08)$ & $1.34(1.08)$ & $1.90(0.95)$ & $2.45(0.71)$ & $2.82(0.40)$ & $2.94(0.23)$ \\
\hline Frailty Index, mean score (SD) & $0.09(0.05)$ & $0.12(0.05)$ & $0.16(0.07)$ & $0.22(0.08)$ & $0.27(0.09)$ & $0.36(0.09)$ & $0.43(0.08)$ \\
\hline Function Scale, mean score (SD) & $0.05(0.12)$ & $0.11(0.16)$ & $0.15(0.19)$ & $0.27(0.22)$ & $0.45(0.24)$ & $0.71(0.24)$ & $0.87(0.19)$ \\
\hline
\end{tabular}


Index each correlated to a similar degree with age $(0.35$ and 0.29 , respectively); the $3 \mathrm{MS}$ measure of cognition $(0.58$, 0.59); the Cumulative Illness Rating Scale, which measures comorbidity $(0.43,0.48)$; the CSHA Function Score $(0.78$, $0.74)$; and the CSHA rules-based frailty definition (0.67 and 0.65 , respectively). Reliability between the 2 ratings of the CSHA Clinical Frailty Scale assessments was very high (intraclass correlation coefficient $0.97, p<0.001$ ).

Hazard ratios for death and entry into an institutional facility (Table 2) in each case showed increasing risk with increasing frailty (Fig. 1, upper graph). ROC curve analyses

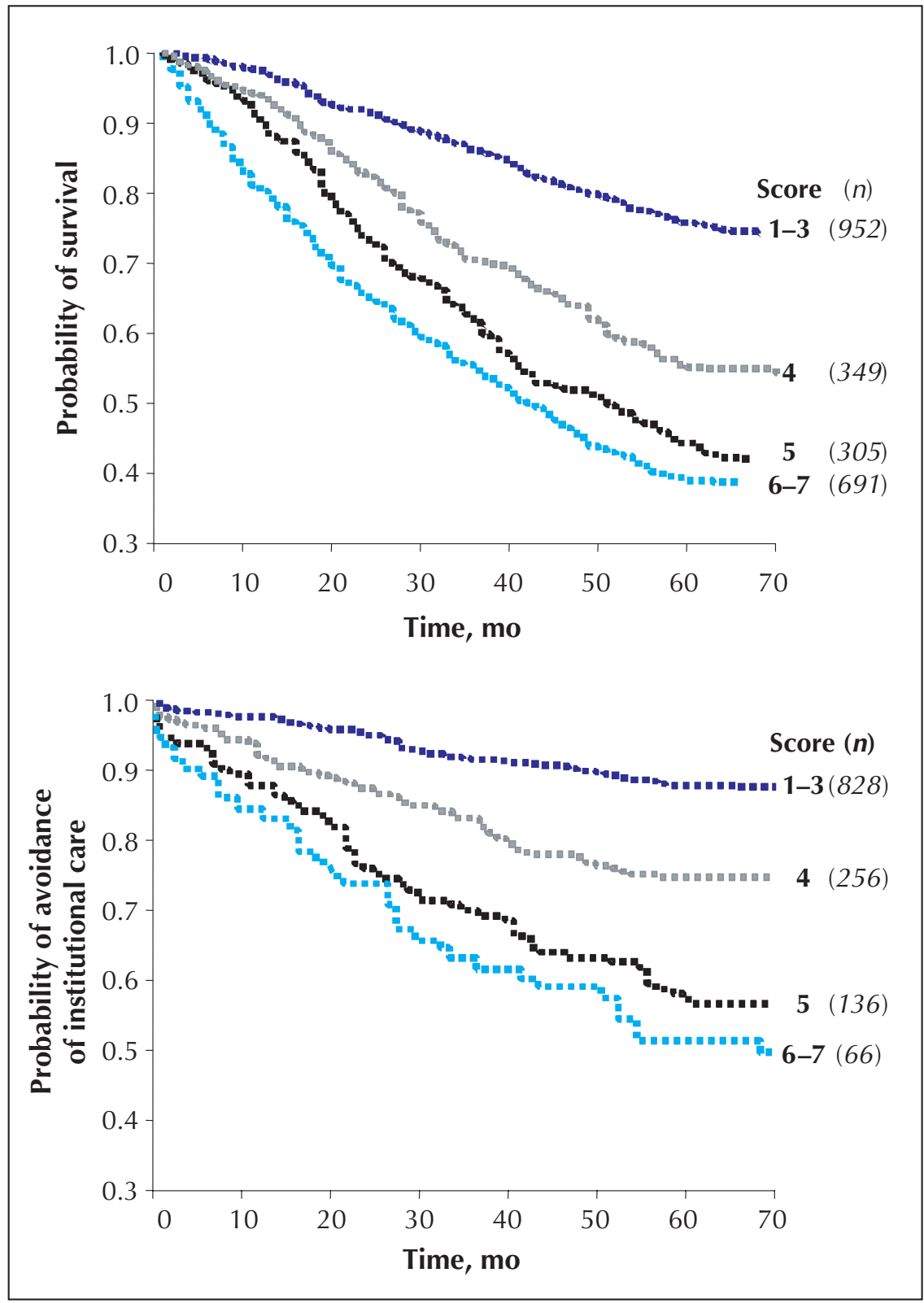

Fig. 1: Kaplan-Meier curves, adjusted for age and sex, for study participants ( $n$ ) over the medium term (5-6 years), according to their scores on the CSHA Clinical Frailty Scale. Some scores were grouped. Top: Probability of survival. Bottom: Probability of avoidance of institutional care. of the CSHA Clinical Frailty Scale and the Frailty Index revealed similar areas under the curves, a performance better than that of the other measures (Table 3). The best result was achieved for near-term mortality (death within 18 months), with an area under the curve of 0.77 .

Similarly, worse frailty was associated with an increased probability of entering an institutional facility (Fig. 1, lower graph). The Clinical Frailty Scale and the Frailty Index had comparable performances in ROC analyses, which again was better than the performance of the $3 \mathrm{MS}$ or Cumulative Illness Rating Scale tools (Table 3). However, the CSHA Function Scale showed significantly better performance than all other measures in assessing risk for entry into an institution.

In multivariable models that adjusted for age, sex and education (Fig. 1), each 1 -category increment of our Clinical Frailty Scale significantly increased the medium-term risks (i.e., those within about 70 months) of death $(21.2 \%$, $95 \%$ CI $12.5 \%-30.6 \%)$ and entry into institutional care $(23.9 \%, 95 \%$ CI $8.8 \%-$ $41.2 \%)$.

\section{Interpretation}

We have shown that the Clinical Frailty Scale is an effective measure of frailty and provides predictive information similar to that of other established tools about death or the need for an institution. The Clinical Frailty Scale is easy to use and may readily be administered in a clinical setting, an advantage over the tools previously developed. For example, counting deficits with the Frailty Index is easy to understand, and powerfully correlates the relation between frailty and death; on the other hand, it requires the physician to consider a list of no fewer than 70 possible disorders. The 7-category Clinical Frailty Scale showed good criterion validity, with a dose-response effect in relation to 5 -year prediction of death or entry into an institutional facility and reasonable construct validity, with worse health characteristics associated with increasing frailty.

The Clinical Frailty Scale mixes items such as comorbidity, cognitive impairment and disability that some other groups separate in focusing on physical frailty. ${ }^{3}$ Although support exists for separate approaches, ${ }^{28}$ consensus does not, ${ }^{1,2}$ 
and there are reasons to be skeptical. The physical frailty approach rests on unspecified assumptions about an unquantitated "physiological reserve"; its predictive validity is no better than a more comprehensive account. Empirically, most elderly patients who are physically frail show some level of disability, although this aspect of the debate depends on the definitions employed ${ }^{29-32}$ and in any case would be captured by our designation of being "apparently vulnerable."

Applying the Clinical Frailty Scale to patients requires judgment. The fabric of individual health has many strands, and it seems likely that some clinicians sometimes used factors not precisely specified in our brief set of descriptors. Some readers might be inclined to view such subjectivity poorly, but we do not see flexibility as a weakness: Different clinicians will emphasize different aspects of illness differently - as in, for example, a psychiatrist and a neurologist each validly concluding, by distinct processes, that a given patient has frontotemporal dementia. Such flexibility is widely validated in similar settings. ${ }^{33-36}$ It also appears to us to be analogous to the advanced computing techniques that we have used in recent inquiries to enhance the performance of the high-dimension Frailty Index. ${ }^{15,37}$ For instance, an artificial neural network can be used to calculate weighted scores, and can significantly improve the Frailty Index's predictive performance over an unweighted version. ${ }^{15}$

What an artificial neural network cannot do, however, is describe which factors most increase risk. This appears to us to be analogous to clinical judgments about the same phenomenon. Both clinical judgment and such advanced computational techniques can be contrasted with a rulesbased frailty approach, which specifies combinations a priori but at the expense of not including the patients that most clinicians would recognize as frail.

The present inquiry showed that the predictive validity of the CSHA's Frailty Index and Clinical Frailty Scale were indistinguishable; moreover, both measures performed better in this regard than did the rules-based frailty definition. On these grounds, and given that rules-based combinations cannot fully embrace the complexity of states in which indi-

Table 3: Receiver operating characteristic (ROC) analyses for adverse outcomes within 70 months

\begin{tabular}{lcc}
\hline & \multicolumn{2}{c}{ Area under the ROC curve } \\
\cline { 2 - 3 } Assessment tool & Death & $\begin{array}{c}\text { Entry into } \\
\text { an institution }\end{array}$ \\
\hline Cumulative Illness Rating Scale & 0.58 & 0.62 \\
Modified Mini-Mental State Examination & 0.64 & 0.69 \\
CSHA rules-based definition of frailty & 0.66 & 0.70 \\
CSHA Function Scale & 0.68 & 0.80 \\
CSHA Frailty Index & 0.69 & 0.72 \\
CSHA Clinical Frailty Scale & 0.70 & 0.75 \\
\hline
\end{tabular}

Note: CSHA = Canadian Study of Health and Aging. vidual people can find themselves, a judgment-based system seems to be a reasonable way to measure relative fitness and frailty. For such an instrument to be used routinely, however, more information is needed about its interrater reliability, which is the subject of additional studies. Until those study results become available, the Clinical Frailty Scale can be used to provide broad guidelines for helping to advise about the best mix of care for elderly patients.

Our data must be interpreted with caution. Although CSHA was population-based, CSHA-2 clinical examinations overrepresent people with cognitive impairment and those in institutions. This probably accounts for the Clinical Frailty Scale's bimodal distribution, with peaks at 3 ("well, with treated comorbid disease") and at 6 ("moderately frail"). On the other hand, the Clinical Frailty Scale showed a wider distribution than might be expected with a purely clinical sample, and our study was large enough to generate estimates with narrow confidence intervals. The only measure of test-retest or interrater reliability available to us was unblinded; that reliability estimate is therefore likely to be higher than would be the case in usual practice. Category 7 appeared to mix 2 groups that seem distinct: terminally ill people (who might still be independent) and those who are totally dependent on others tao carry out their activities of daily living. Although people in category 7 had a high mortality, these subgroups routinely would be distinguished clinically; future users of the scale might do well to subdivide these groups, especially in acute care settings.

We can envisage future roles for CSHA's Frailty Index and Clinical Frailty Scale alike. The judgment-based scale might be better exploited where clinicians are available who have experience in the care of elderly people. The index approach might better serve where such access is unavailable. The index approach also appears to have some important mathematical advantages in its scaling that might lead to novel insights, ${ }^{2,38,39}$ especially into matters such as physiologic reserve, which is often invoked in relation to frailty but little measured. Given the increasingly elderly population, and the particular challenge posed by elderly people who are frail, the important questions for researchers now are how to measure frailty more precisely and how to better translate frailty measurement into clinically sensible tools and practices.

\section{This article has been peer reviewed.}

From the Division of Geriatric Medicine, Dalhousie University, Halifax, NS (Rockwood, Song, MacKnight, Mitnitski); the Division of Geriatric Medicine, McGill University, Montréal, Que. (Bergman); the Division of Geriatric Medicine, University of Calgary, Calgary, Alta. (Hogan); and the Department of Epidemiology and Community Medicine, University of Ottawa, Ottawa, Ont. (McDowell)

Competing interests: None declared.

Contributors: Kenneth Rockwood designed the study, wrote the first and final drafts of the manuscript, and supervised the analyses. Xiaowei Song and Arnold Mitnitski conducted and verified all the analyses. (Arnold Mitnitski and Kenneth Rockwood previously devised and tested the Frailty Index.) Kenneth Rockwood, Chris MacKnight, David Hogan and Howard Bergman examined patients. Ian McDowell, Chris MacKnight and David Hogan commented on and revised interim drafts. All authors contributed to and approved the final published version and support the presented results. 
Acknowledgements: This analysis was supported by grants from the National Health Research Development Program of Health Canada (grant no. 6603-1417-55) and the Queen Elizabeth II Research Foundation. The data reported in this article were collected as part of the Canadian Study of Health and Aging. The core study was funded by the Seniors' Independence Research Program, through the National Health Research and Development Program, project no. 6606-3954-MC(S). Additional funding was provided by Pfizer Canada Incorporated through the Medical Research Council/Pharmaceutical Manufacturers Association of Canada Health Activity Program, the National Health Research and Development Program, project no. 6603-1417-302(R). The study was coordinated through the University of Ottawa and Health Canada's Division of Aging and Seniors. Additional funds for analysis came from the Canadian Institutes for Health Research (CIHR) gran MOP 62823 and the Dalhousie University Internal Medicine Research Foundation. Kenneth Rockwood and Chris MacKnight receive CIHR support through Investigator and New Investigator awards, respectively. Kenneth Rockwood is also supported by the Dalhousie Medical Research Foundation as Kathryn Allen Weldon Professor of Alzheimer Research. Howard Bergman is Dr. Joseph Kaufman Professor of Geriatric Medicine at McGill University, and David Hogan is Brenda Strafford Foundation Chair in Geriatric Medicine at the University of Calgary.

\section{References}

1. Hogan DB, MacKnight C, Bergman H; Steering Committee, Canadian Initiative on Frailty and Aging. Models, definitions, and criteria of frailty [review]. Aging Clin Exp Res 2003;15(3 Suppl):1-29.

2. Rockwood K, Mitnitski A, MacKnight C. Some mathematical models of frailty and their clinical implications. Rev Clin Gerontol 2002;12:109-17.

3. Fried LP, Ferrucci L, Darer J, Williamson JD, Anderson G. Untangling the concepts of disability, frailty, and comorbidity: implications for improved targeting and care [review]. F Gerontol A Biol Sci Med Sci 2004;59:255-63.

4. Lipsitz LA. Physiological complexity, aging, and the path to frailty [review]. Sci Aging Knowledge Environ 2004;2004:pe16.

5. Fried LP, Tangen CM, Walston J, Newman AB, Hirsch C, Gottdiener J, et al.; Cardiovascular Health Study Collaborative Research Group. Frailty in older adults: evidence for a phenotype. 7 Gerontol A Biol Sci Med Sci 2001;56: M146-56.

6. Morley JE, Perry HM III, Miller DK. Editorial: something about frailty [review]. 7 Gerontol A Biol Sci Med Sci 2002;57:M698-704.

7. Rockwood K, Fox RA, Stolee P, Robertson D, Beattie BL. Frailty in elderly people: an evolving concept [review]. CMA7 1994;150(4):489-95.

8. Wells JL, Seabrook JA, Stolee P, Borrie MJ, Knoefel F. State of the art in geriatric rehabilitation. Part I: review of frailty and comprehensive geriatric assessment [review]. Arch Phys Med Rehabil 2003;84:890-7.

9. Chin A Paw MJ, Dekker JM, Feskens EJ, Schouten EG, Kromhout D. How to select a frail elderly population? A comparison of three working definitions. $\mathcal{F}$ Clin Epidemiol 1999;52:1015-21.

10. Strawbridge WJ, Shema SJ, Balfour JL, Higby HR, Kaplan GA. Antecedents of frailty over three decades in an older cohort. 7 Gerontol B Psychol Sci Soc Sci 1998;53:S9-16.

11. Canadian Study of Health and Aging Working Group. Disability and frailty among elderly Canadians: a comparison of six surveys. Int Psychogeriatr 2001; 13(Suppl 1):159-68.

12. Rockwood K, Stadnyk K, MacKnight C, McDowell I, Hébert R, Hogan DB. A brief clinical instrument to classify frailty in elderly people [letter]. Lancet 1999;353(9148):205-6.

13. Chin A Paw MJ, de Groot LC, van Gend SV, Schoterman MH, Schouten EG, Schroll M, et al. Inactivity and weight loss: effective criteria to identify frailty. 7 Nutr Health Aging 2003;7:55-60.

14. Mitnitski AB, Song X, Rockwood K. The estimation of relative fitness and frailty in community-dwelling older adults using self-report data. 7 Gerontol A Biol Sci Med Sci 2004;59:M627-32.

15. Song X, Mitnitski A, MacKnight C, Rockwood K. Assessment of individual risk of death using self-report data: an artificial neural network compared with a Frailty Index. 7 Am Geriatr Soc 2004;52:1180-4

16. Rockwood K, Howlett SE, MacKnight C, Beattie BL, Bergman H, Hebert $\mathrm{R}$, et al. Prevalence, attributes, and outcomes of fitness and frailty in community-dwelling older adults: report from the Canadian Study of Health and Aging. 7 Gerontol A Biol Sci Med Sci 2004;59:1310-7.

17. Jones DM, Song X, Rockwood K. Operationalizing a frailty index from a standardized comprehensive geriatric assessment. 7 Am Geriatr Soc 2004;52: 1929-33.

18. CSHA Working Group. Canadian Study of Health and Aging: study methods and prevalence of dementia. CMA7 1994;150(6):899-913.

19. CSHA Working Group. The incidence of dementia in Canada: the Canadian Study of Health and Aging Working Group. Neurology 2000;55:66-73.

20. Rockwood K, Wolfson C, McDowell I. The Canadian Study of Health and Aging: organizational lessons from a national, multicenter, epidemiologic study. Int Psychogeriatr 2001;13(Suppl 1):233-7.

21. Streiner DL, Norman GR. Health measurement scales: a practical guide to their development and use. 3rd ed. Oxford: Oxford University Press; 2003. p. 4-13.

22. Teng EL, Chui HC. The Modified Mini-Mental State (3MS) examination. 7 Clin Psychiatry 1987;48:314-8.

23. Conwell Y, Forbes NT, Cox C, Caine ED. Validation of a measure of physical illness burden at autopsy: the Cumulative Illness Rating Scale. 7 Am Geriatr Soc 1993;41:38-41.

24. American Psychiatric Association. Diagnostic and statistical manual. 3rd ed, revised. Washington: The Association; 1987.

25. Graham JE, Rockwood K, Beattie BL, Eastwood R, Gauthier S, Tuokko H, et al. Prevalence and severity of cognitive impairment with and without dementia in an elderly population. Lancet 1997;349:1793-6.

26. Ebly EM, Hogan DB, Parhad IM. Cognitive impairment in the nondemented elderly: results from the Canadian Study of Health and Aging. Arch Neurol 1995;52:612-9.

27. Metz CE. Basic principles of ROC analysis. Semin Nucl Med 1978;8:283-98

28. Ferrucci L, Guralnik JM, Studenski S, Fried LP, Cutler GB Jr, Walston JD; Interventions on Frailty Working Group. Designing randomized, controlled trials aimed at preventing or delaying functional decline and disability in frail, older persons: a consensus report. 7 Am Geriatr Soc 2004;52:625-34.

29. Nourhashemi F, Andrieu S, Gillette-Guyonnet S, Vellas B, Albarede JL, Grandjean H. Instrumental activities of daily living as a potential marker of frailty: a study of 7364 community-dwelling elderly women (the EPIDOS study). 7 Gerontol A Biol Sci Med Sci 2001;56:M448-53

30. Schuurmans H, Steverink N, Lindenberg S, Frieswijk N, Slaets JP. Old or frail: What tells us more? 7 Gerontol A Biol Sci Med Sci 2004;59:M962-5.

31. Gill TM, Allore H, Holford TR, Guo Z. The development of insidious disability in activities of daily living among community-living older persons. $A m$ 7 Med 2004;117:484-91.

32. Binder EF, Schechtman KB, Ehsani AA, Steger-May K, Brown M, Sinacore $\mathrm{DR}$, et al. Effects of exercise training on frailty in community-dwelling older adults: results of a randomized, controlled trial. 7 Am Geriatr Soc 2002;50: 1921-8.

33. Studenski S, Hayes RP, Leibowitz RQ, Bode R, Lavery L, Walston J, et al. Clinical Global Impression of Change in Physical Frailty: development of a measure based on clinical judgment. 7 Am Geriatr Soc 2004;52:1560-6.

34. Charlson ME, Sax FL, MacKenzie CR, Fields SD, Braham RL, Douglas RG Jr. Assessing illness severity. Does clinical judgement work? 7 Chronic Dis 1986;39:439-52.

35. Charlson ME, Hollenberg JP, Hou J, Cooper M, Pochapin M, Pecker M. Realizing the potential of clinical judgment: a real-time strategy for predicting outcomes and cost for medical in patients. Am F Med 2000;109:189-95.

36. Torres OH, Munoz J, Ruiz D, Ris J, Gich I, Coma E, et al. Outcome predictors of pneumonia in elderly patients: importance of functional assessment. $\mathcal{F}$ Am Geriatr Soc 2004;52:1603-9.

37. Song X, Mitnitski A, Cox J, Rockwood K. Comparison of machine learning techniques with classical statistical models in predicting health outcomes. Medinfo 2004;2004:736-40

38. Mitnitski AB, Mogilner AJ, MacKnight C, Rockwood K. The accumulation of deficits with age and possible invariants of aging. ScientificWorldfournal 2002;2:1816-22.

39. Rockwood K, Mogilner AJ, Mitnitski AB. Changes with age in the distribution of a frailty index. Mech Ageing Dev 2004;125:517-9.

Correspondence to: Dr. Kenneth Rockwood, Centre for Health Care of the Elderly, 1421-5955 Veterans' Memorial Lane,

Halifax NS B3H 2E1; fax 902 473-1050;

kenneth.rockwood@dal.ca 


\section{Appendix 1: List of variables used by the Canadian Study of Health and Aging to construct the 70-item CSHA Frailty Index}

- Changes in everyday activities

- Head and neck problems

- Poor muscle tone in neck

- Bradykinesia, facial

- Problems getting dressed

- Problems with bathing

- Problems carrying out personal grooming

- Urinary incontinence

- Toileting problems

- Bulk difficulties

- Rectal problems

- Gastrointestinal problems

- Problems cooking

- Sucking problems

- Problems going out alone

- Impaired mobility

- Musculoskeletal problems

- Bradykinesia of the limbs

- Poor muscle tone in limbs

- Poor limb coordination

- Poor coordination, trunk

- Poor standing posture

- Irregular gait pattern

- Falls
- Mood problems

- Feeling sad, blue, depressed

- History of depressed mood

- Tiredness all the time

- Depression (clinical impression)

- Sleep changes

- Restlessness

- Memory changes

- Short-term memory impairment

- Long-term memory impairment

- Changes in general mental functioning

- Onset of cognitive symptoms

- Clouding or delirium

- Paranoid features

- History relevant to cognitive impairment or loss

- Family history relevant to cognitive impairment or loss

- Impaired vibration

- Tremor at rest

- Postural tremor

- Intention tremor

- History of Parkinson's disease

- Family history of degenerative disease
- Seizures, partial complex

- Seizures, generalized

- Syncope or blackouts

- Headache

- Cerebrovascular problems

- History of stroke

- History of diabetes mellitus

- Arterial hypertension

- Peripheral pulses

- Cardiac problems

- Myocardial infarction

- Arrhythmia

- Congestive heart failure

- Lung problems

- Respiratory problems

- History of thyroid disease

- Thyroid problems

- Skin problems

- Malignant disease

- Breast problems

- Abdominal problems

- Presence of snout reflex

- Presence of the palmomental reflex

- Other medical history

\section{Clinical trial registration}

CMAJ will consider clinical trials for publication only if they have been registered in a publicly accessible clinical trials registry before the enrolment of the first patient. This policy applies to trials that start recruiting on or after July 1,2005 . For trials that began enrolment before this date, registration is required by Sept. 13, 2005. The criteria for acceptable registration are described in CMAJ (2005;172[13]:1700-2). 